\title{
Retraction: Influence of maternal diet during lactation and use of formula feeds on development of atopic eczema in high risk infants
}

On 28 October 2015, The BMJ retracted this article, published in 1989:

Chandra RK, Puri S, Hamed A. Influence of maternal diet during lactation and use of formula feeds on development of atopic eczema in high risk infants. BMJ 1989;299:228-30, doi:10.1136/bmj.299.6693. 228.

The $B M J$ has retracted the article after receiving a copy of an inquiry into the research of R K Chandra, which was conducted by the Memorial University of Newfoundland and completed in August 1995. The university did not publish the inquiry report at the time. Nor did it notify the editors of journals that had published articles by Chandra that were considered in the report. The $B M J$ obtained a copy of the report when it came into the public domain as a result of Chandra taking and losing a legal action against the Canadian Broadcasting Corporation (CBC), which aired television programmes about Chandra in 2006.

The inquiring committee experienced great difficulty with its work, but its final conclusion was that "scientific misconduct has been committed by Dr Chandra." It looked at three studies and found that:

"absolutely no raw data (or files) of any kind were exhibited"

"the Committee cannot identify anyone who did the recruiting, cannot identify anyone who did or remembers a significant amount of work"

"the coauathors had little or very likely nothing to do with the work"

"it is unbelievable that there are essentially no hospital records to support the study in question" "the committee cannot accept that the Carnation study was done anywhere near to completeness or with the accuracy reported in the Annals of Allergy and Journal of Clinical Nutrition, For that matter, the same can probably be said for the Mead Johnson work published in the British Medical Journal."

When asked by The BMJ in 2015 why it had not published the report in 1995, Memorial University of Newfoundland said that the report "was the product of a flawed investigation process and could not be relied upon." In the CBC programmes, however, a university spokesman said that the university had not acted on the report because of legal threats from Chandra.

The university further told The BMJ: "In the spirit of being helpful, we acknowledge that over the years serious questions have been raised about the 1989 publication, leading to much controversy. If [The] BMJ decides to retract the paper on the basis of evidence apart from the findings of the 1995 report, then we would understand your decision in this regard."

The BMJ is retracting the paper because of the 1995 report, and because of the convincing evidence given in the $\mathrm{CBC}$ television programmes and the court case that the work of R K Chandra is not to be trusted.

For more information, see The BMJ's feature article ${ }^{1}$ and editorial, ${ }^{2}$ published on 28 October 2015. White C. Ranjit Chandra: how reputation bamboozled the scientific community. BMJ
2015;351:h5683.

2 Smith R, Godlee F. A major failure of scientific governance. BMJ 2015;351:h5694.

Cite this as: BMJ 2015;351:h5682

๑ BMJ Publishing Group Ltd 2015 